\title{
Practice and Thinking on Undergraduate Training Model Based on the Group Guidance
}

\author{
Liangfei Dong \\ School of Environmental \& Safety Engineering, Changzhou University, Changzhou 213164, China \\ dlf@cczu.edu.cn
}

Keywords: Undergraduate education; Group Guidance; training mode; teaching reform.

\begin{abstract}
In order to strengthen the overall guidance of all aspects of undergraduate study, to promote the exchange of teachers and students, train students with good study habits and improve students' comprehensive ability, the School of Environmental and Safety Engineering, Changzhou University proposed and piloted the Group Guidance mode for undergraduate. Group Guidance is carried out in groups divided from professional class; the instructors are from staff room. Guidance for students focuses on students' career planning, learning methods, and scientific research training, etc., usually in the form of group discussions to enhance the interaction and communication, and to give students suggestions, guidance and help. But there are some problems such as time coordination, interest mobilized different modes and effects, and the lack of support and sustain during the implementation, further research is needed by the department of teaching management with setting up a special topic.
\end{abstract}

\section{Introduction}

In traditional education, there is disconnection between teaching and learning. The professional teachers exchange with students rarely, usually leave right after class, and hardly meet with students after school. This does not meet the basic criteria of education, and is not conducive to improving the quality of talent cultivation. Tutorial system has brought good effect on talents cultivation, which makes many countries to follow suit in the higher education. In our country's current higher education training mode, the tutorial system in general is widely adopted for graduate and doctoral education. Some key universities has adopted it in undergraduates cultivation, but the range is very limited[1].Tutorial system is the need for reform of higher education, an effective means of personalized training, and help enhance the exchange of teacher and student and improve the students' comprehensive ability. Class instructor and class teacher (or tutor) are now configured in universities typically, so that they are to play their role in educating and teaching respectively. Instructors are responsible for the daily management and education, to give students education and guidance in thought and behavior, mainly on aspects of student life; Tutor of students gives guidance through knowledge study and research practice, in order to improve students' scientific research ability [2]. But in fact the current class teacher or tutor is nominal, on the one hand is the class teacher as a professional teacher, who has heavy teaching and research tasks, one teacher guides up to 30 students, and cannot concern to every student, not even to mention the personality guidance; on the other hand, there are scheduling issues in the collective guidance, such guidance is normally outside school hours, it is very hard to find a right time for both teacher and all students, so this guide happens seldom each year with a mere formality. However the future trend of the university development is that the tutor should conduct the college students from the aspects such as ideological quality, life style, psychological development, career planning and the ideal goal comprehensively [3].

To comprehensively improve the quality of higher education, the Ministry of Education issued the "Opinions on How to Improve Quality of Higher Education" (the "Higher Education 30") in 2012, of which Article 5 "Innovative Training Model" proposed "to encourage development due to own characteristics of the colleges and universities, to explore the training model integrated development with scientific base, practical skills and cultural literacy.", "to support undergraduates involved in research activities, early into the projects, early into the laboratory, and early into the team." and so on. In May 2013, to further improve the level of specialty construction and the quality of personnel 
training continuingly, Changzhou University performed the system of "Person in Charge of the Specialty" in all undergraduate programs. The major of Water and Wastewater Engineering in School of Environmental and Safety Engineering, combined with the core idea of engineering education accreditation system "student-centered, concerned about the growth of all students", chose a sophomore class as pilot, with participation of all teachers from the Staff Room, to explore the new undergraduate training mode of Group Guidance. After a year of practice, some achievements are harvested, this paper aims to analyze and summarize the gains and losses, in order to provide a reference for the future student guide and training.

\section{Objectives and programs of the Group Guidance}

Professional education is an important function of higher education, students' ideological status, career planning and personality culture have a great relationship with professional education. Tutorial system in undergraduate cultivation is helpful for students to build a reasonable knowledge structure, promoting the comprehensive qualities of students; is beneficial to cultivate innovative talents in accordance with their aptitude; to improve employment competitiveness and to promote teaching and learning; is conducive to the implementation of credit system, and to promote the reform of class teaching [4].After full understanding the state of mind of students, tutor can link the students' professional learning to future employment and career planning, and the professional development to the social development. Tutor can also guide students to establish a correct outlook on life, world outlook and values, help students establish the correct life goals, thus contributing to promoting the initiative of learning [5]. According to the existing problems of class tutor system, the new system of Group Guidance is proposed to carry out the study guiding effectively with full participation of teachers from staff room and the class in the group. Taking the major of Water and Wastewater Engineering as example, there are a total of 12 teachers in staff room, and 31 students in Water Class 112, which can be divided into 12 teams for study guiding based on the number of instructors. Group Guidance begins mainly from the following aspects in order to strengthen the guidance and capacity-building for students.

(1) Student management and guidance. The tutor and guided students pair to a number of groups, which can combine the ideological education with professional education, manage the students decentralized to reduce the stress of centralized management effectively, and can find each student's life and learning problems promptly in order to give pertinent help and guidance.

(2) Study and postgraduate admittance examination guidance. Guiding students to formulate the study plan of every semester and select courses, to help select extracurricular learning materials and references, to cultivate the good habits of after-school self-study, especially the skills of problem founding, problem analysis and problem solving. Taking postgraduate examination is beneficial to developing students' interest for further academic studies, and help create a good style of study. Guiding students for postgraduate examination and giving relative counseling are also an important job of tutors.

(3) Research ability training. Combined with the research projects and research fields, tutor puts forward some research topics and exchanges with students. Through literature search, data compilation and analysis, students' skills for professional literature review and presentation are trained; through participation in experimental studies, water quality analysis and data processing, students' research capabilities are developed.

(4) Academic research and innovative ability training. Based on scientific research platform and the use of teacher's scientific research ability, the students' scientific research consciousness and research ability will be cultivated and promoted, so as to improve the students' academic innovation ability [6]. Instructor should meet and exchange regularly with students with regard of professional and academic questions in learning and literatures reading. Students prepare the PPT presentation, through discussion and communication to improve their academic accomplishment. Guiding and organizing students to apply for the SRT projects, training their ability to independently solve 
practical problems by hosting or participating in research projects, and guiding them for innovative thinking and practices.

(5) Realization of comprehensive guide for students. Students' professional learning is a gradual process; different stages have different learning needs and tasks [7]. Group Guidance begins from undergraduate grade 2, even from grade 1 , so tutors have opportunity to guide students throughout the whole undergraduate phases, can dynamically understand the changes of students' learning, interests and psychological aspects of life, help students determine their life goals and to guide them fully in advance, which can be more effective in promoting students' growth and development, conducive to the cultivation of talents.

Specific implementation plans are:

To organize a starting guide meeting for the pilot class, in which all teachers from staff room and classmates participated, teachers introduced themselves about the giving curriculum, research fields and current research projects, and also hobbies, specialty and requirements for guiding students; students communicated with relevant teachers combined with their hobbies and interested professional direction, then teachers left their contact information for further consultation after meeting, the group list was determined about a week later, and was recorded in the faculty. Each instructor met his group and the student in charge of each group was elected to start Group Guidance. Instructors were required to record the details of each guidance for inspection; and the group leaders of students were also asked to record the guidance including participator, problems and opinions, which can be directly reflected to tutors or indirectly by the teacher in charge of the specialty. At the end of each semester, tutors should write an evaluation report for guiding students and the summary of Group Guidance, in order to promote students for their learning performance.

\section{Group Guidance Summary}

After the group dividing, the teams carried out various forms of guidance activities, including application for technological innovation projects, participation in research projects, literature search and social practices, etc. Most of the students could participate actively, and got the positive impact in the aspects of ideas, study attitudes and research and innovation capacity. Overall, through a year of practice, Group Guidance achieved good results, the students thought the forms of guidance generally well, which was basically to achieve the desired purpose.

\subsection{Main results.}

(1) Professional teachers involved in the Group Guidance to ensure the guiding chances for all students, to reduce the blindness and randomness of professional courses learning, to enhance the systematic and scientific learning, and to effectively compensate for many defects and deficiencies of credit system [8]. In particular, influenced by the knowledge structure and professional experience of instructors, students' comprehensive ability has improved significantly.

(2) The teachers' enthusiasm of teaching and research is mobilized, and the sense of urgency to improve education quality is enhanced. Before the start of Group Guidance, students could choose professional teachers according to their interests and future orientation bidirectionally. After the implementation of Group Guidance the groups regularly submitted summary and collectively showed their guiding results. Therefore, professional teachers will feel pressure and be forced to improve their own professional level, to reform the teaching methods, to update teaching content, and to improve the capability of organization and coordination, education and guidance, and scientific research.

(3) Students' comprehensive ability of scientific research and practices is strengthened. In the traditional undergraduate teaching, teaching is one way of 'training" activities with teachers to students, attention to the training of students' comprehensive ability is not paid. The implementation of Group Guidance reflects the combination of teaching and extracurricular activities, emphasizing the practical ability of students [2]. The professional teachers guide the students in literature review, social practices, extracurricular experiments and SRT projects selection and fulfillment, which could help students accomplish something in their interested areas. 
(4) In favor of communication among relevant parties, promoting the overall development of students. Group Guidance increases the contact opportunities of students with tutors, during the evaluation on students' achievements and scholarships by all levels of university, school and department, with reference to the views of instructors will make the evaluation more objective and comprehensive, and could help students better understand their own shortcomings and make improvements.

\subsection{Main problems.}

Group Guidance is a new way and new model to explore the higher education, this system is designed to guide students inside and outside of class comprehensively. As a new education management model, some success is achieved in practice. Of course, since the Group Guidance is still in experimental stage, there is no ready-made experience for reference and learning, problem is inevitable. Mainly in the following areas:

(1) Time coordination. How to coordinate the tutor and the student's schedule, to give the necessary guidance for undergraduates without affecting the teacher's tasks of teaching and scientific research; on the other hand, for the students, how to organize their own extracurricular activities, to well converge the school plan, future development with teacher's professional education, and to maintain periodic communication and exchange with teacher. In addition, for the guidance requirements, it is not only advocated for teacher to contact the students, also required for students to communicate with the tutor initiatively, in order to play the enthusiasm of both sides, to form the positive interaction and to enhance the effectiveness of the guidance [9].

(2) Interest mobilized. There is still much work to finish with plan in terms of professional and research interest of students. Sophomore cannot find appropriate extracurricular research projects with the knowledge of a few basic courses, and the guidance for implementation of SRT projects is needed from tutor to strengthen with a professional perspective.

(3) Guidance form and results. Group Guidance has no pre-specified certain patterns in the form of exchange between students and instructors, but is determined by the group according to its own circumstances regarding the purpose of guidance. Some groups are conducted by the instructors, literature reading and group discussion are arranged, or the instructors allow students to participate in their own research projects and organize to apply for SRT projects; some groups are student-led, the students regularly contact tutors to meet for consultation of learning and life issues; some groups communicate even through the network, resulting in different guidance effect. Therefore, further research is needed to analyze and summarize the effects of different guidance forms, in order to find the best form of Group Guidance through discussion.

(4) Support and sustain. Each tutor guides 2-3 students in spare time for free, it is difficult to ask them for more input, and the results or quality are difficult to assess. The college should consider of how to give guidance activities necessary material and financial support and sustain, in order to exert the instructors' initiative and enthusiasm, so the Group Guidance can play an active role in the work of personnel training and improvement of the overall quality of students [2]. For the implementation of a system, if there is no effective management measures and powerful institutional guarantee, it finally could only have gone to waste [10].

\section{Conclusions and Suggestions}

Group Guidance is carried out in groups divided from professional class; the instructors are from staff room. Guidance for students focuses on students' career planning, learning methods, and scientific research training, etc., usually in the form of group discussions to enhance the interaction and communication, and to give students suggestions, guidance and help. Group Guidance forms a relatively fixed relationship between students and teachers, the overall guidance can be achieved at university.

Guidance Group is a new mode of education management, which helps enrich the connotation of students' ideological education, combine the teaching and educating people well, is conducive to individualized education and helping students achieve personal development goals. But there are 
some problems such as time coordination, interest mobilized different modes and effects, and the lack of support and sustain during the implementation, further research is needed by the department of teaching management with setting up a special topic. Realizable and practical implementation plan should be put forward combined with the pilot construction and professional training program revision, in order to promote interaction and coordinated development of teaching and learning, moreover to improve the students' overall capacity and quality of higher education.

\section{References}

[1]. Y. Xue, "The perspective of ideological and political education of undergraduate tutorial system research,” East China Normal University, April 2012. (In Chinese)

[2]. N. Zhu and Y. Xue, "Effect of Group Tutor System on major matching of college students," Heilongjiang Researches on Higher Education, vol. 12, pp. 25-28, December 2011. (In Chinese)

[3]. W.Y. Lin, “The discussion of tutor system for college students,” Education Exploration, vol. 10, pp. 68-69, June 2014. (In Chinese)

[4]. Y.D. Chen, "Students based on the needs of undergraduate tutorial system and discusses to J college as a case,” Jiangxi Normal University, June 2013. (In Chinese)

[5]. P.X. Wang, Z.H. Tang, H. Xiao, "Change toward an Equal Relationship between College Teachers and Students-A Discussion on the Class Counselor System at a Four-Year College,” Education and Modernization, vol. 10, pp. 62-67, 73, March 2008. (In Chinese)

[6]. R. Li, "The tutorial system implementation and optimization research in colleges and universities,” Henan University, May 2011. (In Chinese)

[7]. J.H. Han, "Thoughts on the implementation and improvement of the Undergraduate Tutorial System,” Journal of Zhejiang Institute of Medial \& Communications, Hangzhou, vol. 16, pp. 61-63, January 2008. (In Chinese)

[8]. C.R. Lamao, "Thinking on the implementation and improvement of University undergraduate student tutor system,” Journal of Qinghai Normal University (Philosophy and Social Science Edition), vol. 18, pp.142-144, March 2005. (In Chinese)

[9]. J. Luo, "Research on the implement of tutorial system - based on the survey of $\mathrm{N}$ nationwide universities,” China Higher Education Evaluation, vol. 3, pp. 27-32, June 2014. (In Chinese)

[10]. L.F. Li, "Undergraduate tutorial system in colleges and universities implement - the present study to university academic honor student tutor system as an example,” Hubei University, May 2013. (In Chinese) 